\title{
Representações dos professores sobre saber histórico escolar
}

Oldimar Ponies Cardoso

\section{RESUMO}

Este texto apresenta alguns dos resultados de uma pesquisa de campo educacional que procura compreender como quatro professores de História do Ensino Médio de uma mesma escola representam o saber histórico escolar criado cotidianamente por eles. A análise dos dados sugeriu que as representações dos professores são marcadas pela oposição aos assim chamados "professores tradicionais" e "historiadores positivistas".

Palavras-chave: ensino de História, cotidiano escolar, representações de professores

A expressão "saber histórico escolar" e sua variante "conhecimento histórico escolar" são utilizadas com muita frequêência nas discussões sobre o ensino de História no Brasil, pelo menos desde a década de 1980. Essas duas expressões estão fundamentadas na idéia de que o saber escolar não é apenas o resultado da simplificação e da vulgarização do conhecimento acadêmico, mas que, pelo contrário, muitos dos saberes existentes na escola e presentes nas representações de professores e alunos foram criados "pela própria escola, na escola e para a escola" (CHERVEL, 1990, p. 181). As conclusões das pesquisas de André CHERVEL $(1990 ; 1998)$ demonstram que a criação de saber escolar é resultado da ação cotidiana de todos os professores, inclusive daqueles que se acreditam meros reprodutores do conhecimento acadêmico.

Nos últimos 20 anos, os diversos textos acadêmicos (SILVA; ANTONACCI, 1990; BITTENCOURT, 1997; ABUD, 2001), relatos de professores (CRUZ, 1984; CORDEIRO, 2000, p. 211-215) e documentos oficiais (SÃO PAULO, 1989; SÃO PAIJLO, 1992; BRASIL, 2000; BITTENCOURT, 1998) que afirmaram a existência

1 Mestre em Educação - Doutor em Educação pela FEA - USP. 
de um saber ou conhecimento histórico escolar não definiram o que ele significa para os agentes que realizam sua criação. Visando compreender como os professores de História representam o saber histórico escolar, foi realizada uma pesquisa de campo com os quatro professores de História do Ensino Médio de uma escola da Rede Oficial de Ensino do Estado de São Paulo. Neste texto, são utilizados dados relativos a três desses professores, apresentados a seguir como SUJEITO 1, SUJEITO 3 e SUJEITO 4. Durante todo o ano letivo de 2002, suas aulas foram observadas e analisadas de acordo com a teoria das representações, formulada por Henri LEFEBVRE (1983), e com a metodologia da observação participante interpretativa, proposta por Frederick ERICKSON (1985)

Tradicionais e Positivistas

A análise das representações realizada nessa pesquisa sugere que os professores identificam como inimigos do saber histórico escolar os "professores tradicionais" e os "historiadores positivistas". Apesar de esses dois inimigos serem empiricamente inexistentes, os professores pesquisados orientam algumas de suas ações no combate a eles.

Dentre os professores observados, o SUJEITO 1 foi aquele que apresentou de forma mais clara uma espécie de aversão ao que chamava de "tradicional", especialmente na distinção que fazia entre o ensino que realizava no $1^{12}$ ano do Ensino Médio e o que realizava no $2^{2}$ e no $3^{ }$ano. Os alunos das duas últimas séries eram definidos por essa professora como "acostumados ao ensino tradicional", enquanto os alunos do 1ำ ano poderiam participar de um ensino "não-tradicional". É interessante observar que essa professora não conseguia classificar o ensino que dizia realizar no $1^{0}$ ano, a não ser por oposição àquilo que denominava "tradicional". o que ela chamava de ensino "tradicional" pode ser descrito como o uso da estratégia ponto-explicação, ou seja, essa professora passava na lousa um texto de livro didático durante os 40 primeiros minutos da aula e nos últimos 10 minutos explicava esse texto, reproduzindo oralmente o que tinha acabado de escrever e às vezes acrescentando alguma informação a ele. Já no $1^{1}$ ano, onde dizia realizar um ensino "não-tradicional", a professora dividiu os temas presentes em seu planejamento entre cinco grupos compostos por cinco ou seis alunos. Cada grupo recebeu um tema relativo ao 
contexto do século XVI europeu para trabalhar. No início do ano letivo, diante das reclamações dos alunos - que não queriam trabalhar em grupo ou queriam formar grupos com mais de seis componentes -, a professora resolveu sortear os grupos e os temas. Após esse sorteio, os alunos passaram todas as aulas seguintes tendo que produzir um texto sobre o tema sorteado para seu grupo. Mais nenhuma orientação foi dada pela professora, que a cada aula apenas retirava do armário da sala diversos livros didáticos de Ensino Fundamental e os deixava à disposição dos alunos. Aparentemente sem entender o que deviam fazer, os alunos nada perguntavam à professora, permanecendo por quatro aulas sem realizar o que havia sido solicitado por ela. A professora apenas advertia que a responsabilidade de elaboração do texto era deles, e que essa atividade valeria nota. Depois dessas quatro primeiras aulas, nas quais apenas dois alunos realizaram o trabalho solicitado, os outros alunos começaram a se reunir nos grupos e a realizar aquilo que eles chamavam de resumir os textos dos livros didáticos de Ensino Fundamental sobre o tema do seu grupo. Ao procurar romper com práticas suas chamadas de "tradicionais", o SUJEITO 1 pareceu simplesmente parar de ensinar, deixando toda a responsabilidade das atividades realizadas em sala por conta dos alunos.

Além da assim designada escola tradicional, outro inimigo imaginário presente nas representaçōes dos professores estudados são os denominados professores positivistas. No sentido historiográfico, o termo positivismo foi inventado pelos historiadores ligados à revista acadêmica Annales d'Histoire Économique et Sociale, publicada na França a partir de 1929, para designar pejorativamente seus inimigos (DOSSE, 1992, p. 21). Apesar de constantemente associado aos historiadores Charles Victor LANGLOIS (1863-1929), Charles SEIGNOBOS (1854-1942) e Leopold von RANKE (1795-1886), esse termo não designa uma tradiçăo historiográfica de existência concreta. Se os assim chamados historiadores positivistas eram inimigos reais ou imaginários da autodenominada École des Annales, cabe à Historiografia responder. Mesmo que algum dia existiram de forma contundente e ameaçadora, a ponto de serem dignos de debates e combates, como nos fazem crer os historiadores franceses do século XX, os chamados historiadores positivistas certamente não são inimigos reais dos professores de História contemporâneos. Tanto quanto a assim chamada escola tradicional, os historiadores positivistas existem apenas 
na imaginação dos professores de História, mas nem por isso deixam de influenciar suas representações.

Dentre os professores observados nessa pesquisa, O SUJEITO 3 constitui um caso exemplar nesse sentido. Essa professora declarou tentar distanciar-se de práticas "positivistas", que parecem ser definidas por ela como aquelas que tentam impor uma verdade aos alunos. Essa tentativa pode ser responsável pela recorrência de um tipo específico de atividade em seu trabalho. Mais da metade de suas aulas observadas no segundo semestre foram organizadas sob a forma de trabalhos em grupo que culminavam na apresentação de um seminário sobre um tema diferente para cada um deles. Durante a preparação desses seminários, os alunos não recebiam orientações sobre como eles deveriam ser apresentados, tanto no tocante à forma da apresentação quanto no que diz respeito aos conteúdos que deveriam ser contemplados. Os alunos sistematicamente realizavam aquilo que definiam como "resumir" textos de livros didáticos de Ensino Fundamental. Esse "resumo" sequer era revisado, sendo feito diretamente nas folhas de papel sulfite que seriam apresentadas ou nos arquivos do software PowerPoint. Ao tentar fugir de um referencial "positivista", esse sujeito deixou de interferir na produção dos alunos e, portanto, em seu processo de aprendizagem.

As polarizações que parecem ser operadas nas representações dos professores entre o novo ou o positivista e o crítico ou o tradicional, provavelmente contribuem para que suas representações sobre o saber histórico escolar pareçam maniqueístas, conforme analisado a seguir.

\section{Diálogos Simulados}

Um exemplo de episódio que poderia ser classificado como "diálogo simulado" foi observado numa aula do SUJEITO 4, na turma C do 20 ano de Ensino Médio, no dia 05 de agosto. Ele a começou colocando na lousa um mapa político da América do Sul. Solicitou aos alunos que observassem 0 mapa e então perguntou a eles: "- Por que o Brasil não se despedaçou em vários países como a América Espanhola?". Não deu muito tempo para os alunos pensarem e respondeu: "- Com a fuga da família real". A esta resposta, seguiu outra pergunta: "- Mas por que a família real fugiu de Portugal?". 
Diante da perplexidade dos alunos, sem esperar muito pela resposta, disse: "Por causa das Guerras Napoleônicas". Após essa resposta, fez nova pergunta: "- Mas qual é a relaçăo entre as Guerras Napoleônicas e a fuga da família. real?. L assim seguiu por toda a auka, utilizando apenas retoricamente o formato de pergmtas e respostas. Em momento algum, auxiliou um aluno a elaborar melhor sua tentativa de resposta ou subdividiu uma pergunta em outras mais simples para facilitar as respostas dos alunos. O SUJEITO 4 parecia. não estar realmente interessado em dialogar com os alunos, pois senão teria parcelado sua primeira pergunta em diversas outras, para que pelo menos alguns deles atingissem sua resposta.

A mesma simulação de diálogo com os alunos pôde ser observada numa alla do SUJETY 3, realizada na turma 3D no dia 30 de setembro. Ela consistiu numa avaliaçäo dos seminários realizados pelos alunos a respeito das eleiçōes que comenim naguele ano para os cargos de presidente da república, govemador, senador e deputado. Esses seminários foram realizados como um trabalho de natureza interdisciplinar, envolvendo as disciplinas de História, Geografia e Filosofia, em todas as tumas do Ensino Médio. Os grupos de alunos, depois de um mês de trabalho durante o terceiro trimestre letivo, realizaram no auditório da escola uma apresentação sohe a historia a as propostas de um dos partidos políticos definidos pelos professores: PT' PPS, YPB, PSDB, PMDB, PFL e PSB. Depois da realização de todos os seminários, ela propos uma avaliação desse trabalho, com os alunos dispostos em círculo na sala Nesca aula, os alunos até fularam, mas suas palavras não tiveram efeito sobre o discurso da professora. O fáto de as declarações dos alunos contradizerem seu discuso não alterou a conclusão à qual ela pretendia chegar:

SUJEITO 3: "- As apresentaçoes foram praticamente leitura de programa de partido, não foi? Por outro lado, quem pesquisou o partido, quem foi atrás, aprendeu pelo menos aquele partido que estava pesquisando. É verdade ou não é? A origem daquele partido... E de certa forma, quem se deu ao trabalho de prestar atenção no que era lido, infelizmente era lido, deu pra dar uma comparada na história dos partidos. Não deu? [...] De um modo geral, esse trabalho serviu para abrir um pouquinho a cabeça dos terceiros colegiais. Quem daqui já vai votar esse ano? [...] Para aqueles que vão votar, o debate mudou alguma coisa? [...]"

GRIPO IE ALUNOS GRITANDO EM CORO: "- Não!" 
SujlitTo 3: "- Não? (Quem gostaria de falar. Para quem mudou a idéia? O debate mudou a idéia da eleição que você tinha antes?"

ALuNA X: "- Não. Todo mundo rouba, é tudo igual..."

ALIINA Y: "- Lu vou votar no Enéas."

SuJEITO 3: "- Explica teu voto. É: assim, por que você acha que é o Enéas?

ALUNA Y: "- Ah, porque assim, professora, a gente tem que dar uma chance para ele, porque ninguém nem já deu uma chance para ele, nem no horário político [...]"

SuJEITO 3: Para quem vai votar eu sugiro que vão à internet ou no diretório do partido, pesquisem a história desse partido, as propostas desse partido, o que esse partido quer, porque uma pessoa não é o partido. [...] Eu até teria algo a te dizer do Enéas. Mas vê o que o PRONA pretende, o que o Enéas... a história do Enéas. Então gente, as fontes vocês já sabem, não sabem? Onde procurar? Façam isso com o seu partido, com a pessoa que vocês escolheram. Porque só dessa forma... a gente só vai mudar se a gente tiver conhecimento das coisasa."

Com essa aula, a professora parecia querer dizer aos alunos que, apesar de as apresentações não terem significado o aprendizado da prática de seminário, pelo menos garantiram que eles abrissem "um pouquinho a cabeça" e soubessem escolher melhor seus candidatos. Todos os alunos que se manifestaram disseram exatamente o contrário do que ela esperava. Mesmo assim, ela insistiu no que tinha planejado dizer a eles.

Em todos os exemplos de aula analisados anteriomente, o que os sujeitos channan de tentativas de diálogo, com raras exceções, se assemelham mais a monólogos. Nas situações de aula analisadas, a rejeição de uma prática representada como tradicional ou positivista - a aula expositiva - parece ter fomentado a mudança para outra tão pouco efetiva quanto ela. Apesar do intuito de executar aquilo que se convencionou chamar de "aula expositiva dialogada", para fazer face ao imaginário professor tradicional, o resulado obtido foi principalmente um monólogo.

Trabalhando em Grupo desamparado

Além das aulas expositivas, analisadas anteriomente, os trabalhos de elaboração de textos em grupo propostos pelos professores observados constituem bons focos para a descrição de suas representações sobre o saber histórico 
escolar. Nessas atividades também é aparente a tentativa de desvincular sua prática daquilo que é chamado de tradicional ou positivista. Especialmente no caso dos trabalhos em grupo, representados pelos sujeitos dessa pesquisa como uma oportunidade privilegiada de criação de saber histórico escolar, essa visão maniqueista de seu trabalho afetou diversos aspectos das açōes realizadas cotidianamente com os alunos. Talvez com o intuito de permitir que os alunos criassem suas próprias interpretações, os professores acabaram por minimizar suas intervenções nesses trabalhos, comprometendo seriamente sua finalidade.

o exemplo mais claro de um trabalho em grupo realizado sem a devida intervenção dos professores ocorreu no terceiro bimestre letivo como proposta de natureza interdisciplinar, envolvendo as disciplinas de História, Geografia e Filosofia, em todas as turmas do Ensino Médio. Os grupos de alunos, depois de un mês de trabalho, realizaram no auditório da escola uma apresentação sobre un dos partidos políticos definidos pelos professores: PT, PPS, PPB, PSDB, PMDB, PHL e PSB. Os grupos do 12 ano apresentaram o que os professores chamaram de "programas dos partidos" - suas crenças políticas mais básicas -; os do 2" ano expuseram o que os professores chamaram de "história dos partidos", e os do 3" ano apresentaram as "propostas dos partidos" - para o exercício dos cargos em disputa naquela eleição específica. Para preparar sua apresentacão, cada grupo teve pelo menos seis aulas para levantar as informacóes necessárias em materiais que eles deveriam trazer de casa-jomais, revistas, livros ou outros materiais coletados nos diretónios dos respectivos partidos. Agumas dessas aulas ocorreram no laboratório de informática, permitindo que os alunos procurassem informações na intemet. Mais nenhuma orientação foi dada. Os alunos não receberam indicações dos professores sobre como tratar as infomações encontradas. Na aula realizada na turma $2 \mathrm{C}$ no dia 9 de setembro, um aluno que perguntou a SUJEITO 4 onde poderia encontrai a historia de determinado partido, recebeu como resposta que a única fonte confiável era um livro didático indicado por ele - que continha apenas um parágrafo de informação sobre esse partido. 0 professor ainda acrescentou que o aluno deveria ignorar "as propagandas políticas e os histónicos presentes nos sites dos próprios partidos. Na prática, como essas eram as únicas fontes acessíveis aos alunos e eles não aprenderam a lidar com elas, as apresentações consistiram em leitura de páginas impressas dos sites dos partidos, 
como pôde ser observado na aula realizada em 26 de setembro na turma 3D pelo SUJEITO 3. Sem o tratamento adequado, essa informação não interessava aos alunos ouvintes. Na avaliação dos professores, os alunos perderam a chance de realizar uma boa atividade, pois os textos não deveriam ser lidos, mas falados. Em suas representações, parecem não se dar conta de que a diferença entre ler mecanicamente e expor oralmente passa pela compreensão dos conteúdos, o que somente ocorreria se eles fossem ensinados pelos professores.

Outro trabalho em grupo com essas características, realizado na aula do SUjETTO 3 na turma 3D em 19 de agosto, consistiu na elaboração em grupo pelos alunos de uma linha do tempo, ou seja, uma lista de fatos históricos ordenados cronologicamente e antecedidos pelas datas nas quais ocorreram. Depois de algumas aulas de preparaç̧ão, copiando informações de livros didáticos de Ensino Fundamental para follias de papel sulfite, os alunos expuseram fatos aparentemente sem sentido para eles. Nem sequer sabiam pronunciar as palavras que escreveram. Na continuação das apresentações desse trabalho, algumas semanas depois, na aula de 9 de setembro, o primeiro grupo a se apresentar também apenas leu o cartaz, parecendo não compreender o que lia. A única ressalva da professora sobre essa apresentação foi a de que os alunos não tinham colocado nenhum fato sobre o Brasil no cartaz. Como os alunos leram com alguma seguranç̧a, a exposição parece ter sido considerada boa pelo restante da sala. 0 segundo grupo a se apresentar nesse dia leu um papel que estava nas mãos dos alunos, e não exposto na lousa em forma de painel. Os demais alunos reclamaram do fato porque expuseram seu próprio painel em forma de varal - colado em um barbante - e exigiam que os outros também o fizessem. Em momento algum reclamaram de não conseguir observar o painel. Mas isso eles provavelmente não queriam nem podiam, pois as letras de todos os cartazes para. apresentação eram muito pequenas. Era impossivel ouvir a voz de alguns alunos, mas não houve reclamação, porque muitos alunos não prestavam atenção, mas liam jornal ou jogavam no telefone celular. A apresentação terminou com críticas da professora ao grupo, solicitando ao próximo que fosse melhor. As críticas não atingiram o primeiro grupo, que realizou uma apresentação aparentemente tão sem sentido quanto a do segundo.

Esses episódios nos quais os alunos foram deixados à própria sorte diante de fontes e conteúdos que desconheciam, descrevem bem uma das representações dos professores sobre o saber histórico escolar. A de que ele pode 
ser criado pelos alunos em trabalhos realizados em grupo sem a sua intervenção. Nas palavras dos sujeitos, essa ausência de intervenção em nenhum momento foi entendida como ausência de ensino por parte do professor, mas como autonomia do aluno. Eles declararam que os alunos precisavam aprender a pensar por conta própria e os professores não deveriam querer colocar as idéias em suas cabeças. Alguns sujeitos associaram essa suposta busca de autonomizaçăo dos alunos, que resultou invariavelmente em ausência de intervenção do professor, a uma tentativa de não direcionar seus alunos. Os sujeitos dessa pesquisa parecem confundir ensino e doutrinação, o que faz da recusa à doutrinação uma recusa a ensino. Para não correr o risco de dirigir seus alunos, o que aproximaria os sujeitos dessa pesquisa de seus inimigos imaginários, os professores abrem mäo de ensinar História, como pôde ser observado na recorrente estratégia de realização de trabalhos em grupo sem a sua orientação. Contraditoriamente, em suas representações, essa parece ser uma das formas de criação de saber histórico escolar.

Considerações Winais

As representaçóes dos professores sobre o saber histónico escolar descritas neste trabalho parecen estar sempre mais vinculadas à forma que ao conteúdo do ensino realizado por eles. Sua reflexão sobre o ensino que realizam envolve decidir constantemente qual estratégia será utilizada, qual produto resultará desse trabalho ou como será realizado o gerenciamento do tempo e do espaço da sala de aula. Porém, não apresentam o mesmo empenho na seleção dos conteúdos que serão ensinados. Parecem separar "didáuica" e "ciência de referência", na tentativa de privilegiar a primeira delas. O saber escolar é representado como mero facilitador da assimilação de uma "ciência de referência" pelos alunos, e não como uma disciplina autônoma em constante transformação no contexto escolar - como o define André CHERVEL (1990, p. 181-182). Daí a maior ênfase às estratégias que ao conteúdo histórico, representados como dois elementos dissociáveis. Isso pode ser resultado da fuga constante dos inimigos imaginários existentes nas representacões dos professores. A negação permanente daquilo que os professores chamam de positivista ou tradicional os afasta da preocupação com os conteúdos, sempre associados aos 
"fatos históricos", tão privilegiados pelos "positivistas" quanto odiados por seus inimigos.

Bibliografia

ABUII), Kátia Maria. Conhecimento histórico e ensino de História: a produção de conhecimento histórico escolar. XIV ENCONTRO REGIONAL DE HISTÓRIA. SUJEITOS NA HISTÓRIA: PRÁTICAS E REPRESENTAÇÕES. 1998. São Paulo. Encontros com a Históric. № 2. Bauru: EDUSC, 2001, p. 127-141.

Bl'T'TENCOUR'T, Circe Maria Fernandes. Capitalismo e cidadania nas atuais propostas curriculares de Historia in (org.). O saber bistórico na sala de aula. SP: Contexto, 1997, p. 11-27.

Propostas curriculares de História: continuidades e transformações in BARRETO, ELBAS. S. (org.). Os curriculos do ensino fundamenial para as escolas brasileirtas. SP: Autores Associados / Fundação Carlos Chagas, 1998, p. 127-161.

BRASIL. Ministeŕrio da Educação. Secretaria de Educação Fundamental. Parâmetros Curriculares Nacionais: Iistória e Geografia. 13 edição: 1997. RJ: DP\&A, 2000.

CILRVEL, André História das disciplinas escolares: reflexões sobre um campo de pesquisa. Teoria \& Educhisăo, Porto Alegre, № 2, p. 117-229, 1990.

. Lo cullure scolaire: une approche historique. Paris: Belin, 1998.

CORIEIRO, Jaime Francisco Parreira. A bistória no ceniro do debate: as propostas de renovação do ensino de Ilistória nas décadas de setenta o oitenta. Araraquara: Laboratório Editorial INESP, 2000.

CRIIZ, Heloísa de Faria. Ensino de História, da reprodução à produção de conhecimento in SILVA, Marcos Antônio da (org.). Repensando a História. RJ: Marco Zero, 1984, p. 25-29.

DOSSE, François. A Historia em migalbas: dos Annales à Nova História. SP: Ensaio / Campinas: Editora da Unicamp, 1992.

ERICKSON, Frederick. Qualitative Methods in Research on Teaching in WITTROCK, Merlin C. (org.) Htondbook of Research on Teaching. NY: Macmillan, 1985, p. 119-161.

LEFEBVRE, Henri. La presencia y la ausencia: contribución a la teoría de las representaciones. México: Fondo de Cultura Económica, 1983. 
SÃO PAULO (Estado). Secretaria da Educação. Coordenadoria de Estudos N Normas Pedagógicas. Propasia Curricular para o Ensino de História: $1^{\circ}$ grau. SP: SE / CENP, 1989.

Proposta Curricular para o Ensino de História: $1^{0}$ grau. SP: SE / CENP, 1992.

SILVA, Marcos Antônio da; ANTONACCI, Maria Antonieta Martines. Vivências da contramão: produção de saber histórico e processo de trabalho na escola de $1^{10}$ e $2^{2}$ graus. Revisia Brasileira de História, São Paulo, Vol. 9, № 19, p. 9-29, 1990.

\section{Teachers representations on school's historical knowing}

\section{ABSTRACT}

This text presents some results of a field research on teaching that attempts to understand how four History teachers of the same school represent the school's historical knowing created daily by them. Data analysis suggested that the teachers representations are marked by the opposition to the so-called "traditional teachers" and "positivist historians".

Key words: history teaching, school's everyday, teachers representations 